\title{
A meta-analysis of acupuncture techniques for smoking cessation
}

\author{
Adrian R White, Karl-Ludwig Resch, Edzard Ernst
}

\begin{abstract}
Objective-To determine the effectiveness of acupuncture for smoking cessation and to examine whether any individual aspect of trials is associated with an effect.

Data sources-All randomised controlled trials of acupuncture for smoking cessation that were listed in computerised databases or reference lists of relevant articles.
\end{abstract}

Study selection-All randomised singleblind studies that compared acupuncture with sham acupuncture.

Data extraction-Methodological data were extracted for quality assessment. Outcome data were extracted for rates of total smoking cessation at three intervals: early after treatment and after six and $\mathbf{1 2}$ months follow up.

Data synthesis-Results were expressed as odds ratios of success over failure in intervention over control groups. The combined odds ratio for all studies was calculated. Repeated meta-analyses were subsequently performed on subsets of studies combined according to defined characteristics: acupuncture technique, number of attendances, country of origin, status of journal, and control procedure. The overall quality of studies was poor. The combined odds ratio for smoking cessation calculated for the earliest results after the end of treatment was $1.20(95 \%$ confidence intervals $(95 \%$ CIs) $=0.98$ to 1.48). The combined odds ratio for smoking cessation after six months was 1.29 $(95 \% \mathrm{CI}=0.82$ to 2.01$)$, and after 12 months was $1.03(95 \% \mathrm{CI}=0.73$ to 1.46$)$. There were no significant effects of relevance among subsets of studies grouped according to defined characteristics.

Department of Complementary Medicine,

Postgraduate Medical School, University of Exeter, Exeter, UK A R White K-L Resch

E Ernst

Correspondence to: Department of Complementary Medicine, Postgraduate Medical School, University of Exeter, 25 Victoria Park Road, Exeter EX2 4NT; a.r.white@exeter.ac.uk

Received 14 March 1997 Revision received 7 August Revision received 7 August

Accepted 5 September 1997
It has been estimated that up to $16 \%$ of residents in the United Kingdom have used acupuncture at some time, ${ }^{1}$ and a recent survey found that $15 \%$ of the population would consider complementary medicine for smoking cessation. ${ }^{2}$ The use of acupuncture for addictions originated from a chance observation that opiate withdrawal symptoms were relieved among Hong Kong addicts who received acupuncture treatment. ${ }^{3}$ Subsequent studies in animals that had been rendered dependent on drugs lent some support to the idea that acupuncture may have an effect on withdrawal symptoms. ${ }^{4-7}$

Acupuncture has been considered for a role in smoking cessation because of its effects in releasing neurotransmitters. Details of these effects in humans are still unclear, as indeed are the neurochemical mechanisms of nicotine addiction and withdrawal. In addition to evidence that acupuncture may release endogenous opioids, ${ }^{8}$ there is some evidence suggesting a possible role for serotonin (5-HT), noradrenaline (norepinephrine), and cholecystokinin in acupuncture analgesia. ${ }^{89}$ as well as in nicotine craving and withdrawal. ${ }^{10}$ It seems likely that increased dopamine levels (through inhibition of monamine oxidase inhibitor B) are involved in nicotine addiction ${ }^{11}$ but the role of acupuncture in dopamine metabolism is still uncertain. ${ }^{8}$

There is contradictory evidence on whether acupuncture has a clinically useful effect in smoking cessation. In one review, Lewith ${ }^{12}$ concluded that "acupuncture is as good as nicotine replacement therapy." On the other hand, ter Riet et $a l^{13}$ performed a criteria-based, systematic review of randomised controlled trials (RCTs) and concluded that better quality studies were more likely to be negative. Two further meta-analyses ${ }^{14}{ }^{15}$ concluded that there was no evidence that acupuncture had an effect in smoking cessation. However, these analyses involved only eight and six studies respectively, and may be open to bias as they included open trials. The range of techniques used in these trials was wide, and the possibility remains that one technique may be more effective than another.

Two basic acupuncture techniques are reported. Firstly, needles may be inserted while the patient relaxes for 10 to 20 minutes. The needles are then removed. Points in the ear are commonly used in the English-speaking world, whereas French practitioners more commonly use points in the face. Acupuncture points on the body may be needled at the same time, and electrical stimulation may be applied. Secondly, an indwelling needle may be inserted into one or more points in the ear and held in 
place for one or two weeks with an adhesive dressing. The subject is instructed to press the needle whenever cravings occur. The number and frequency of treatments vary between practitioners.

We conducted a fresh meta-analysis of RCTs, using a comprehensive search strategy, to determine the effectiveness of acupuncture in smoking cessation and to compare the effectiveness of different techniques.

\section{Methods}

DATA SOURCES

A literature search was performed of computerised databases held by Medline (1974-1996), Embase, the British Library, CISCOM (Centralised Information Service for Complementary Medicine, Royal College of Complementary Medicine, 60 Great Ormond Street, London WC1N 3JF), and Science Citation Index, combining the terms "clinical trials", "acupuncture", and "smoking" or "tobacco". Previous reviews of acupuncture for addiction were obtained and their reference lists searched. The results of contacting experts in the field and searching for "grey" literature, performed for one recent review, ${ }^{13}$ were included, but the procedures were not repeated. Copies of original articles were obtained and, where necessary, authors were contacted to obtain further data or clarify details.

STUDY SELECTION

All studies were selected in which subjects were randomised by an appropriate method to receive acupuncture or a control intervention. Only subject-blind studies, in which the control group received a sham form of acupuncture, were included in the primary analyses. However, all studies were included in the comparison of acupuncture with different control procedures. There were no restrictions on acupuncture technique or length of follow up, but only studies published in English, French or German were included.
DATA EXTRACTION

The outcome measure used in the analysis was complete cessation of smoking at three time points: the earliest measurement after the intervention, and after six and 12 months, follow up. Participants' reports of smoking cessation were used as biochemical confirmation was not available in any of the studies. Where necessary, results were recalculated to include all drop-outs, who were assumed to have relapsed. Sustained cessation rates were used when available in preference to point prevalence of abstinence.

\section{QUALITY ASSESSMENT}

Each paper was first assessed for appropriateness of method of randomisation, concealment of randomisation, minimisation of practitioner interaction, and sample size calculation. Each study was then scored according to the method of ter Riet et al ${ }^{13}$ using a list of 18 predefined criteria which included validation of outcome and duration of follow up. The maximum possible score is 100 . The original authors allocated points to each criterion according to their estimate of its importance, the highest score being 15 points for "Good quality of acupuncturist mentioned." Examples of other criteria were randomisation (12), adequate description of acupuncture procedure, subjectblinding, and at least 50 subjects in each group (10 points each).

DATA SYNTHESIS

The data were analysed using custom-written software known as RevMan 2.1a. This programme was developed and published by the Cochrane Collaboration to provide accessible and standardised methods of performing meta-analyses for the Cochrane database of systematic reviews. It provides the facility of performing repeated meta-analyses on various combinations of studies which have been selected according to defined criteria. In the present study, total numbers of subjects included in each group, and the numbers who

Table 1 Details of random controlled trails of acupuncture for smoking cessation

\begin{tabular}{|c|c|c|c|c|c|}
\hline Author & $n$ & Treatment & $\begin{array}{l}\text { Sustained } \\
\text { treatment }\end{array}$ & Control procedure (s) & $\begin{array}{l}\text { Duration of } \\
\text { follow up }\end{array}$ \\
\hline \multicolumn{6}{|l|}{ Sham-controlled RCTs } \\
\hline Clavel $^{19}$ & 996 & Facial (+ nicotine/placebo gum) & NA & Sham (+ nicotine/placebo gum) & 13 months \\
\hline Gilbey $^{21}$ & 92 & Auriculo & i.n. & Sham & 3 months \\
\hline Gillams $^{22}$ & 81 & Auriculo & i.n. & $\begin{array}{l}\text { (a) Sham } \\
\text { (b) Behaviour }\end{array}$ & 6 months \\
\hline Lacroix $^{24}$ & 117 & Face & NA & Sham & 2 weeks \\
\hline Lagrue $^{25}$ & 154 & Face & NA & Sham & \\
\hline Lamontagne $^{26}$ & 75 & Auriculo & NA & $\begin{array}{l}\text { (a) Body, for relaxation } \\
\text { (b) Waiting list }\end{array}$ & 6 months \\
\hline Martin $^{29}$ & $\begin{array}{l}134 \\
126\end{array}$ & $\begin{array}{l}\text { (a) Auriculo } \\
\text { (b) Auriculo + EA }\end{array}$ & i.n. & $\begin{array}{l}\text { (a) Sham } \\
\text { (b) Sham }\end{array}$ & 6 months \\
\hline Parker $^{30}$ & $\begin{array}{l}21 \\
20\end{array}$ & $\begin{array}{l}\text { (a) Auriculo } \\
\text { (b) Auriculo + EA }\end{array}$ & i.n. & $\begin{array}{l}\text { (a) Sham } \\
\text { (b) Sham }\end{array}$ & 6 weeks \\
\hline Steiner ${ }^{31}$ & 22 & Body + auriculo & i.n. & Sham & 4 weeks \\
\hline $\begin{array}{l}\text { Vandevenn } \mathrm{e}^{32} \\
\text { RCTs using other controls }\end{array}$ & 200 & Face + body & NA & Sham & 12 months \\
\hline Clavel $^{17}$ & 665 & Facial & NA & $\begin{array}{l}\text { (a) Nicotine gum } \\
\text { (b) Timed cigarette case }\end{array}$ & 13 months \\
\hline Cottraux ${ }^{20}$ & 558 & Auriculo + facial & NA & $\begin{array}{l}\text { (a) Behaviour } \\
\text { (b) Placebo } \\
\text { (c) Waiting list }\end{array}$ & 12 months \\
\hline Labadie $^{23}$ & 130 & Auriculo + face + body & NA & Medical & 12 months \\
\hline Leung $^{27}$ & 95 & Auriculo & i.n. & $\begin{array}{l}\text { (a) Behaviour } \\
\text { (b) Waiting list }\end{array}$ & 6 months \\
\hline
\end{tabular}

$\mathrm{EA}=$ electroacupuncture; i.n. $=$ indwelling needle. 


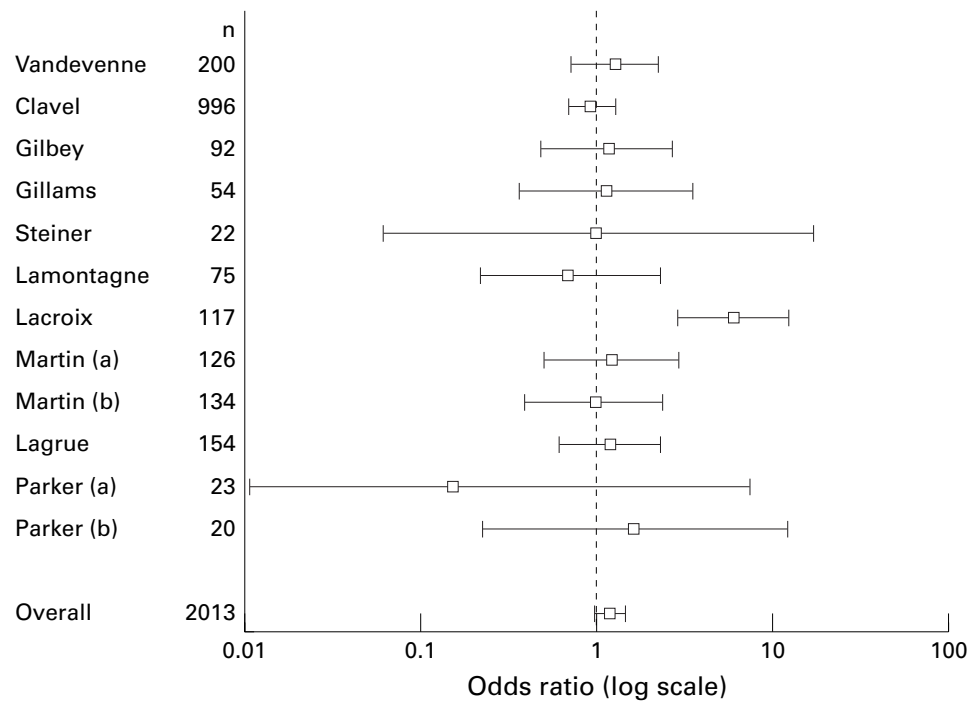

Figure 1 Odds ratios and 95\% confidence intervals for smoking cessation at first assessment after intervention for individual and overall odds ratio. Trials in descending order of quality. $n=$ Number of subjects. Martin and Waite, ${ }^{29}$ and Parker ${ }^{30}$ included separate trials in the reports, labelled (a) and (b) in the figure.

had stopped smoking at specified time intervals (first measure, six months, 12 months) were entered into tables for comparison. Subsequently all studies were allocated to subgroups according to the following characteristics: acupuncture technique, number of attendances, country of origin, status of journal of publication, and control procedure.

The method of analysis selected for this study calculated the odds ratio (OR) for each trial, that is, the ratio of successes to failures in the genuine treatment group, divided by the same ratio in the sham treatment group, presented on a logarithmic scale. Weighting studies according to their inverse variance, the programme computed a combined OR for all trials in the comparison, using the Peto model developed from the Mantel-Haenszel approach. ${ }^{16}$ This method does not involve any assumptions and patients in one trial are only compared with other patients in the same trial. 95\% Confidence intervals (CIs) were calculated from the sums of the individual variances.

\section{Results}

Fourteen reports of RCTs of acupuncture for smoking cessation were found. ${ }^{17-32}$ We have been unable to obtain a copy of an unpublished study by Tschopp which was included in the review by ter Riet et al. ${ }^{13}$ Previous reviews include a study by Machovec and Man. ${ }^{28}$ However, the report does not state that the subjects were randomised and as we were unable to clarify this point with the authors, this study was excluded. Key information from all remaining RCTs is set out in table 1 .

There were 10 reports of studies in which the control group received some form of sham acupuncture, as set out in table 1. However, Martin and Waite ${ }^{29}$ and Parker and Mok $^{30}$ reported two comparisons (two groups receiving different acupuncture procedures, each with its own control group). Data from each of these studies were entered separately. Thus the main analyses included 12 sham-controlled, subject-blinded RCTs. Additional data for the study by Martin and Waite ${ }^{29}$ were obtained from the authors.

Figure 1 gives the ORs for smoking cessation for all studies at the first assessment after the intervention. The combined OR for smoking cessation in the 12 studies was $1.20(95 \% \mathrm{CI}=$ 0.98 to 1.48$)$. The combined OR for smoking cessation after six months was $1.29(95 \% \mathrm{CI}=$ 0.82 to 2.01 ). The two studies that followed up subjects for 12 months produced a combined OR of 1.03 ( $95 \% \mathrm{CI}=0.73$ to 1.46$)$.

QUALITY OF STUDIES

The overall quality of the studies was disappointing. A particular deficiency was the failure to validate smoking cessation by biochemical tests, relying instead on subjects' reports. Other consistent methodological problems were as follows. No report included adequate details to be certain whether an appropriate method of randomisation with adequate concealment was used. No attempt to minimise the influence of the acupuncturist on the subjects was mentioned in 12 of the 14 reports: Gilbey and Neumann ${ }^{21}$ reported minimal interaction by the therapist, and Lacroix and Besancon ${ }^{24}$ arranged for the therapist to be blinded. Although sustained cessation is the aim of any anti-smoking programme, the outcome at six months was measured in only four studies, and at 12 months in only two studies (table 2). A sample size calculation, which should be an essential part of trial design, was only mentioned by Clavel et al. ${ }^{18}$

The lack of methodological rigour is indicated by the quality scores assessed by the method of ter Riet et $a l^{13}$ and shown in table 2 . Studies are presented in descending order of quality in figure 1, and it can be seen that there is no meaningful relation between quality and result. The combined OR for the six better-quality studies which scored 50 points or more was 1.02 (95\% CI $=0.80$ to 1.31 ).

On repeating the quality assessment using the criteria of ter Riet et al, ${ }^{13}$ we found that these authors had awarded the study by Lacroix $^{24}$ zero points for technique. However, there are clear indications in the text that the acupuncturist was of good quality. These details were given in technical language which was presumably not recognised by ter Riet and

Table 2 Sham-controlled random controlled trials of acupuncture for smoking cessation: quality scores (method of ter Riet et al ${ }^{13}$ ) and assessment intervals

\begin{tabular}{|c|c|c|c|c|}
\hline \multirow[b]{2}{*}{ First author } & \multirow[b]{2}{*}{$\begin{array}{l}\text { Quality } \\
\text { score }\end{array}$} & \multicolumn{3}{|c|}{$\begin{array}{l}\text { Outcome measurement intervals } \\
\text { analysed }\end{array}$} \\
\hline & & $\begin{array}{l}\text { Earliest } \\
\text { interval } \\
\text { (weeks) }\end{array}$ & 6 Months & 12 Months \\
\hline Vandevenne $\mathrm{e}^{32}$ & 74 & 6 & + & + \\
\hline Clavel $^{19}$ & 62 & 4 & & + \\
\hline Gilbey $^{21}$ & 59 & 1 & & \\
\hline Gillams $^{22}$ & 57 & 4 & + & \\
\hline Steiner ${ }^{31}$ & 52 & 4 & & \\
\hline Lamontagne $^{26}$ & 50 & 2 & + & \\
\hline Lacroix $^{24}$ & 47 & 2 & & \\
\hline $\operatorname{Martin}^{29}$ & 41 & 3 & + & \\
\hline Lagrue $^{25}$ & 40 & 1 & & \\
\hline Parker $^{30}$ & 34 & 6 & & \\
\hline
\end{tabular}




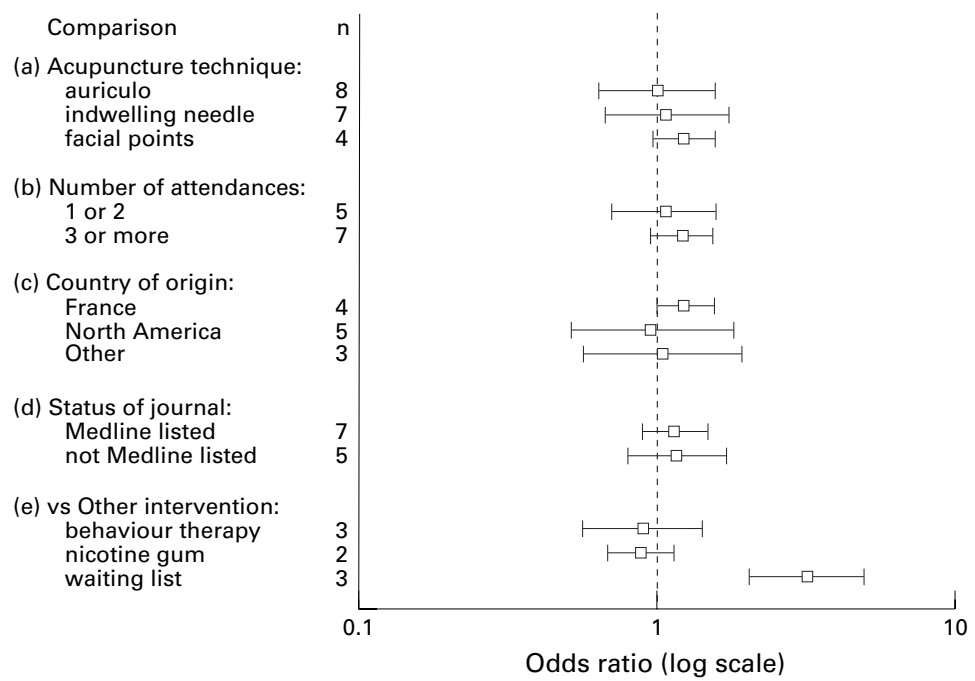

Figure 2 Odds ratios and 95\% confidence intervals for smoking cessation at first assessment after intervention for subgroups of sham-controlled random controlled trials of acupuncture. Comparisons (a) to (d) include sham-controlled studies; comparison (e) includes all randomised studies. $n=$ Number of subjects.

colleagues, none of whom were acupuncturists. This study had been underscored by 25 points. (We would argue that the opinion of a specialist in the area should be consulted when assessing the quality of experience or technique.)

OTHER COMPARISONS

Figure 2 shows that no particular aspect of the studies was identified which led to a result in which acupuncture was superior to sham, whether combining studies with different acupuncture techniques, number of attendances, country of origin, or status of journal. The comparisons with other control groups were limited by small numbers of studies. Acupuncture appears to be as effective for smoking cessation as behaviour therapy, ${ }^{2027}$ but significantly better than waiting-list control $^{202627}$ which, in view of the lack of specific effects shown above, provides evidence of its considerable placebo effect. However, this effect may not persist: after six months there was no difference in outcome (OR 0.99, $95 \% \mathrm{CI}=0.30$ to 3.20 ).

\section{Discussion}

In our analyses, no acupuncture technique was shown to be have greater efficacy than sham acupuncture for smoking cessation. This is consistent with previous meta-analyses. ${ }^{14} 15$ These studies are burdened by methodological inadequacies. A particularly critical limitation was the failure to validate smoking cessation. Other potentially serious sources of bias include inadequate details of randomisation procedures and failure to minimise practitioner influence on the subjects. It is noteworthy that the six studies which made the best attempts to reduce bias, and scored $50 \%$ or more on formal quality testing, also confirmed the lack of efficacy of acupuncture for smoking cessation. Thus the overall negative finding of the present study is likely to be valid.

The problem of the unreliability of the results can be illustrated by considering the single study ${ }^{24}$ which was strongly positive compared with the remaining 11 . This result cannot be explained by the variables examined here, such as acupuncture technique. However, the report did not mention any attempt to minimise or standardise the practitioner's influence on patients. Therefore it seems possible, or even likely, that therapist bias contributed significantly to this positive result.

Acupuncture did prove to be more effective than waiting-list control and therefore appears to have important non-specific effects. Members of the public are likely to continue to approach practitioners for help in stopping smoking while the current interest in acupuncture lasts. Indeed, their preference for this particular form of treatment, the effort of finding a practitioner, and the commitment of paying a fee might usefully increase the motivation to stop.

This review has highlighted the variety of styles of acupuncture which have been tested for smoking cessation, reflecting the absence of any clear hypothesis on the role of acupuncture in smoking cessation, either at mechanistic or behavioural level. Most studies were based empirically on the findings of previous reports. Only one study ${ }^{29}$ was stated to have been designed to test a possible mechanism of action of acupuncture-the release of endogenous opioids, for which there is some evidence. ${ }^{33}$ Although endogenous opioids may be relevant to withdrawal from opiate drugs, their role in nicotine withdrawal is much less certain. On the other hand, there is little evidence that acupuncture influences the level of dopamine which appears to be fundamental to the process of nicotine addiction. ${ }^{11}$

No study was based on a hypothesis that acupuncture might have particular behavioural effects that might assist smoking cessation, for example, by reducing withdrawal symptoms, by inducing euphoria or by increasing motivation and thereby reducing the relapse rate. Data on craving were only presented in one report ${ }^{18}$ in which 318 out of the total of 996 subjects assessed their need for a cigarette after the intervention as a secondary outcome measure. The results do not suggest any influence of either nicotine chewing gum or acupuncture on levels of craving.

There remains the question whether all potential contributions of acupuncture in nicotine dependence have been explored. This study did not uncover evidence that any particular technique of acupuncture was more promising than any other, although the strength of this conclusion is limited by the small number of studies. There were trends in favour of using facial points and of repeating treatment on three or more occasions. These trends hardly amount to a hypothesis for the action of acupuncture on either the neurochemical or the behavioural level which would justify further research at the present time.

It is axiomatic that, if further research into acupuncture for smoking cessation is conducted, this should be to a much higher 
standard of quality than previously. In addition to the need for a clear hypothesis, the major methodological requirements identified are: calculation and recruitment of adequate sample size, appropriate method of randomisation of subjects, concealment of randomisation, minimisation of therapist bias, biochemical validation of smoking cessation, and long-term follow up for at least six months and preferably 12 months.

In conclusion, even the most rigorous trials provide no evidence that acupuncture is superior to sham in smoking cessation. There is also no evidence that one acupuncture technique is superior to another.

1 Fisher P, Ward A. Complementary medicine in Europe. BMF 1994;309:107-11.

2 Mintel Complementary Medicines. Market intelligence report, 1997. London: Mintel, 1997.

3 Wen HL, Cheung SYC. Treatment of drug addiction by acupuncture and electrical stimulation. Asian f Med 1973; 9:138-41.

4 Ng LKY, Douthitt TC, Thoa NB, et al. Modification of morphine-withdrawal syndrome in rats following transauricular stimulation: an experimental paradigm for auricuricular stimulation: an experimental paradigm for

5 Choy YM, Tso W-W, Fung KP, et al. Suppression of narcotic withdrawals and plasma ACTH by auricular elecnarcotic withdrawals and plasma ACTH by auricular elec-
troacupuncture. Biochem Biophys Res Commun 1978; troacupun

6 Cheng RSS, Pomeranz B, Yu G. Electroacupuncture treatment of morphine-dependent mice reduces signs of withdrawal, without showing cross-tolerance. Eur $\mathcal{F}$ Pharmacol 1980;68:477-81.

7 Han JS, Zhang RL. Suppression of morphine abstinence syndrome by body electroacupuncture of different frequencies in rats. Drug Alcohol Depend 1993;31:169-75.

8 Han J, Terenius L. Neurochemical basis of acupuncture analgesia. Anпu Rev Pharmacol Toxicol 1982;22:192-220.

9 Han JS, Ding XZ, Fan SG. Cholecystokinin octapeptide (CCK-8): antagonism to electroacupuncture analgesia and a possible role in electroacupuncture tolerance. Pain 1986;27:101-15.

10 Nutt DJ. Addiction: brain mechanisms and their treatment implications. Lancet 1996;347:31-6.

11 Fowler JS, Volkow ND, Wang G-J, et al. Inhibition of monoamine oxidase B in the brains of smokers. Nature monoamine oxidase B in the brains of smokers. Nature 1996;379:733-6.

12 Lewith GT. The treatment of tobacco addiction. Comp Ther Med 1995;3:142-5.

13 ter Riet G, Kleijnen J, Knipschild P. A meta-analysis of studies into the effect of acupuncture on addiction. $\mathrm{Br} f$ Gen Pract 1990;40:379-82.
14 Law M, Tang JL. An analysis of the effectiveness of interventions intended to help people stop smoking. Arch Intern Med 1995;155:1933-41.

15 Fiore MC, Bailey WC, Cohen SJ, et al. Smoking cessation. Clinical Practice Guideline No 18. Rockville, Maryland: US Department of Health and Human Services, Public Health Service, Agency for Health Care Policy and Research, April 1996. (AHCPR Publication No 960692.).

16 Yusuf S, Peto R, Lewis J, et al. Beta blockade during and after myocardial infarction: an overview of the randomized trials. Prog Cardiovasc Dis 1985;27:335-71.

17 Clavel-Chapelon F, Benhamou S, Company-Huertas A, et al. Helping people to stop smoking: randomised comparison of groups being treated with acupuncture and nicotine gum with control group. BMF 1985;291:1538-9.

18 Clavel F, Paoletti C. Une étude de différents programmes de désintoxication tabagique portant sur près de 1000 volontaires recrutés dans la population générale: résultats à 1 mois. Rev Epidémiol Santé Publique 1990;38:133-8.

19 Clavel F, Paoletti C, Benhamou S. A randomised $2 \times 2$ factorial design to evaluate different smoking cessation methods. Rev Epidémiol Santé Publique 1992;40:187-90.

20 Cottraux JA, Harf R, Boissel J-P, et al. Smoking cessation with behaviour therapy or acupuncture- a controlled study. Behav Res Ther 1983;21:417-24.

21 Gilbey V, Neumann B. Auricular acupuncture for smoking withdrawal. Am $\mathcal{F}$ Acupunct 1977;5:239-47.

22 Gillams J, Lewith GT, Machin D. Acupuncture and group therapy in stopping smoking. The Practitioner (London) 1984;228:341-4.

23 Labadie J-C, Dones J-P, Gachie J-P, et al. Désintoxication tabagique: acupuncture et traitement médical. Gaz Méd France 1983;90:2741-7.

24 Lacroix J-C, Besancon F. Le sevrage du tabac. Efficacité de l'acupuncture dans un essai comparatif. Ann Méd Intern 1977; 128:405-8.

25 Lagrue G, Poupy JL, Grillot A, et al. Acupuncture anti-tabagique. Nouvelle Presse Médicale 1977;9:966.

26 Lamontagne Y, Annable L, Gagnon M-A. Acupuncture for smokers: lack of long-term therapeutic effect in a controlled study. Can Med Assoc F 1980;5:787-90.

27 Leung J-P. Smoking cessation by auricular acupuncture and behavioral therapy. Psychologia 1991;34:177-87.

28 Machovec FJ, Man SC. Acupuncture and hypnosis compared: fifty-eight cases. Am f Clin Hypn 1978;21:45-7.

29 Martin GP, Waite PME. The efficacy of acupuncture as an aid to stopping smoking. $N Z$ Med $\mathcal{f} 1981 ; 93: 421-3$.

30 Parker LN, Mok MS. The use of acupuncture for smoking withdrawal. Am $\mathcal{F}$ Acupunct 1977;5:363-6.

31 Steiner RP, Hay DL, Davis AW. Acupuncture therapy for the treatment of tobacc

32 Vandevenne A, Rempp M, Burghard G. Etude de l'action spécifique de l'acupuncture dans la cure de sevrage tabagique. Sem Hôp Paris 1985;61:2155-60.

33 Clement-Jones V, McLoughlin L, Lowry PJ, et al. Acupuncture in heroin addicts: changes in met-enkephalin and beta-endorphin in blood and cerebrospinal fluid. Lancet 1979;2:380-3. 